УДК615.32.072

\title{
ОПРЕДЕЛЕНИЕ КАЛЬЦИЯ В ПЛОДАХ ОБЛЕПИХИ КРУШИНОВИДНОЙ (HIPPOPHAES RHAMNOIDES L.)
}

\author{
(C) О.В. Тринеева*, А.И. Сливкин \\ Воронежский государственный университет, Университетская пл., 1, \\ Воронеж, 394006 (Россия), e-mail: trineevaov@mail.ru
}

\begin{abstract}
Облепиха является одним из ценнейших источников природного масла, богатого каротиноидами, токоферолами, эссенциальными жирными кислотами, а также большой группы водо- и жирорастворимых витаминов и витаминоподобных соединений, органических кислот, минеральных и других веществ. Минеральные вещества как компонент метаболизма лекарственных растений дополняют и усиливают их лечебное воздействие на организм. Особый интерес вызывает макроэлемент кальций. В настоящее время фармацевтический рынок предлагает достаточно широкий ассортимент лекарственных препаратов, содержащих соли кальция, но, к сожалению, практически все они имеют противопоказания и могут вызывать серьезные побочные эффекты. Поэтому применение лекарственных растений, в которых макро- и микроэлементы находятся в биоусвояемой форме, может быть эффективным для нормализации минерального баланса. В российских и зарубежных нормативных документах в лекарственных субстанциях и лекарственных формах, содержащих кальций, ионы этого металла определяют комплексонометрическим титрованием.

Разработана простая, доступная методика количественного определения кальция в плодах облепихи крушиновидной методом комплексонометрии, которая может быть учтена при разработке современной нормативной документации. Выбраны оптимальные условия извлечения кальция из плодов облепихи крушиновидной. Исследовано влияние процесса высушивания на содержание кальция в исследуемом сырье. Результаты для свежих и высушенных плодов составили соответственно 0,8853 и $1,0057 \%$ (в пересчете на абсолютно сухое сырье), что свидетельствуют об отсутствии влияния процесса сушки на содержание солей кальция в плодах. Доказана перспективность использования плодов облепихи различных способов консервации в качестве дополнительного источника микроэлемента кальция.
\end{abstract}

Ключевые слова: соли кальция, комплексонометрия, плоды облепихи свежие и высушенные, стандартизация.

\section{Введение}

Плоды облепихи по качественному составу и количественному содержанию биологически активных веществ и их воздействию на организм человека превосходят плоды и ягоды многих других растений [1]. Облепиха является одним из ценнейших источников природного масла, богатого каротиноидами, токоферолами, эссенциальными жирными кислотами, а также большой группы водо- и жирорастворимых витаминов и витаминоподобных соединений, органических кислот, минеральных и других веществ [2]. Минеральные вещества как компонент метаболизма растений дополняют и усиливают лечебное воздействие фитопрепаратов на организм (например, они потенцируют адаптогенное действие сборов). Баланс макро- и микроэлементов в лекарственных растениях формируется вследствие функционирования сложных многофазных механизмов концентрирования и аккумуляции этих веществ, на которые влияют различные факто-

Тринеева Ольга Валерьевна - доцент кафедры фармацевтической химии и фармацевтической технологии, кандидат фармацевтических наук, e-mail: trineevaov@mail.ru

Сливкин Алексей Иванович - декан фармацевтического факультета, заведующий кафедрой фармацевтической химии и фармацевтической технологии, доктор фармацевтических наук, профессор, e-mail: slivkin@pharmvsu.ru ры, в том числе видовая специфичность растения. Для подавляющего большинства элементов установлена их биологическая роль [3].

Особый интерес вызывает элемент кальций. Содержание кальция в организме человека колеблется от 1 до 1,5 кг. Недостаток данного элемента (гипокальциемия) наблюдается при большом количестве заболеваний (рахит, остеопороз, снижение

\footnotetext{
* Автор, с которым следует вести переписку.
} 
функции щитовидной железы, хроническая почечная недостаточность, панкереатит, механическая желтуха, аллергия, печеночная недостаточность и др.). Нехватка кальция может наблюдаться и при применении некоторых лекарственных препаратов (противоопухолевых, противосудорожных). В связи с этим в настоящее время фармацевтический рынок предлагает достаточно широкий ассортимент лекарственных средств, содержащих соли кальция, но, к сожалению, практически все они имеют противопоказания и могут вызывать серьезные побочные эффекты. Поэтому применение лекарственных растений, в которых макро- и микроэлементы находятся в биоусвояемой форме, может быть эффективным для нормализации минерального баланса [3, 4].

М.Я. Ловкова и соавторы проанализировали 212 видов лекарственного растительного сырья (ЛРС). Согласно их данным, кальций присутствует во всех видах ЛРС, причем его содержание колеблется от 0,1 мг/г (клубнелуковицы безвременника) до 79,1 мг/г (листья алоэ древовидного).

Цель настоящего исследования - рассмотреть возможность использования титриметрического метода для количественной оценки содержания кальция в плодах облепихи крушиновидной при различных способах ее консервации.

\section{Экспериментальная часть}

В ГФ X, XI изданий, а также в британской фармакопее субстанцию кальция хлорида количественно оценивают комплексонометрически. Этот метод достаточно распространен для анализа лекарственных веществ, которые являются солями щелочноземельных и тяжелых металлов.

Объектом исследования являлись плоды растения рода Ніррорһаёs, собранные в Воронежской области согласно правилам заготовки ЛРС в свежем и высушенном виде. Сушку плодов производили при $\mathrm{t}=$ $60{ }^{\circ} \mathrm{C}$ до остаточной влажности не более $20 \%$.

Количественное определение. Около 4 г сырья (точная навеска) помешают в коническую колбу вместимостью 250 мл, разминают плоды стеклянной палочкой до кашицеобразного состояния и прибавляют 100 мл кислоты хлористоводородной разведенной (8,3\%). Колбу присоединяют к обратному холодильнику, нагревают на кипящей водяной бане в течение 30 мин, периодически встряхивая для смывания частиц сырья со стенок. Затем колбу с содержимым охлаждают до комнатной температуры, фильтруют через бумажный фильтр, смоченный кислотой хлористоводородной разведенной, избегая попадания сырья на фильтр, в мерную колбу вместимостью 200 мл. Частицы сырья в колбе снова заливают 100 мл кислоты хлористоводородной разведенной и выдерживают на кипящей водяной бане в течение 30 мин., фильтруют через тот же бумажный фильтр в мерную колбу. Если требуется, объем извлечения доводят до метки кислотой хлористоводородной разведенной. 20 мл извлечения помещают в колбу для титрования, прибавляют 50 мл воды очищенной, 8 мл 30\% водного раствора натрия гидроксида до $\mathrm{pH}$ 5,0-6,0; 4 мл аммиачного буфера, несколько крупинок индикатора эриохрома черного Т и титруют 0,05 М раствором трилона Б до перехода окраски от красно-вишневой до зеленовато-синей. Попытки оттитровать в извлечении катионы магния в присутствии специфического индикатора пирокатехинового фиолетового не увенчались успехом и показали его отсутствие в плодах. Содержание магния составляет менее $10^{-6}-10^{-7}$ моль/л в извлечении [7-10]. На основании этого делаем вывод, что в извлечении комплексонометрически титруется только кальций в виде кальция хлорида. Содержание кальция в процентах $(\mathrm{X})$ в пересчете на абсолютно сухое сырье вычисляют по формуле:

$$
X, \%=\frac{V \cdot 0,002 \cdot 200 \cdot 100 \cdot 100}{m \cdot 20 \cdot(100-W)}=\frac{V \cdot 200}{m \cdot(100-W)},
$$

где 0,002 - количество кальция, соответствующее 1 мл раствора трилона Б (0,05 моль/л), г; V - объем раствора трилона Б (0,05 моль/л), пошедшего на титрование, в мл; m - масса сырья, г; W - потеря в массе при высушивании сырья, \%.

\section{Обсуждение результатов}

В российских и зарубежных нормативных документах (НД) в лекарственных субстанциях и лекарственных формах, содержащих кальций, ионы этого металла определяют комплексонометрическим ти- 
трованием [5-10]. Данный метод в настоящее время законодательно закреплен в ГФ XI и XII изданий и является методом выбора при оценке количественного содержания катионов кальция и магния в различных объектах фармацевтического назначения. Кроме того, комплексонометрия характеризуется всеми преимуществами титриметрических методик, а именно, простотой, доступностью, малой ошибкой определения, экономичностью, несложной предподготовкой пробы, не требует дорогостоящего оборудования, реактивов, материалов и высококвалифицированного персонала. Все это позволит широко внедрить разработанную методику в практику повседневного рутинного фармацевтического анализа и сделает ее востребованной и доступной для любой лаборатории.

Для установления полноты экстракции кальция из плодов облепихи крушиновидной изучали влияние соотношения сырья и экстрагента, оптимального времени и кратности экстракции (рис. 1, 2), а также pН-экстрагента. Лучшим экстрагентом для выделения кальция является разведеная кислота хлористоводородная при соотношении сырья и экстрагента $1: 50$ (табл. 1 и 2). Оптимальное время экстракции, согласно экспериментальным данным, составило 60 мин (рис. 1), дальнейшее увеличение времени нецелесообразно.

При исследовании влияния рН-экстрагента на выход кальция (табл. 2) установлено, что с уменьшением $\mathrm{pH}$ до 1,0 единицы происходит повышение экстрагируемости кальция. Высокий выход кальция из плодов при использовании кислоты хлористоводородной разведенной обусловлен, скорее всего, растворением солей кальция в изучаемом ЛРС с образованием легкорастворимового хлорида кальция.

С целью выбора оптимальных условий хранения плодов облепихи и исследования стабильности соединений кальция проводили количественное определение кальция в свежих и высушенных плодах. Результаты составили соответственно 0,443 и 0,503\% (в пересчете на абсолютно сухое сырье). Данные рисунка 3 свидетельствуют о том, что процесс сушки не влияет на содержание солей кальция в ЛРС. Небольшое увеличение находится в пределах ошибки определения.

Содержание кальция в плодах облепихи крушиновидной по данным, полученным с помощью разработанной методики, составляет в среднем 1\%. Результаты определения кальция в плодах облепихи в пересчете на абсолютно сухое сырье и метрологическая характеристика методики представлены в таблице 3.

Таблица 1. Влияние соотношения сырья и экстрагента на извлечение кальция из плодов облепихи крушиновидной

\begin{tabular}{c|c}
\hline $\begin{array}{c}\text { Соотношение сырья } \\
\text { и экстрагента }\end{array}$ & $\begin{array}{c}\text { Содержание кальция, } \\
\%\end{array}$ \\
\hline $1: 10$ & $0,443 \pm 0,036$ \\
$1: 25$ & $0,284 \pm 0,023$ \\
$1: 50$ & $0,505 \pm 0,041$ \\
$1: 100$ & $0,489 \pm 0,040$ \\
$1: 200$ & $0,470 \pm 0,042$ \\
\hline
\end{tabular}

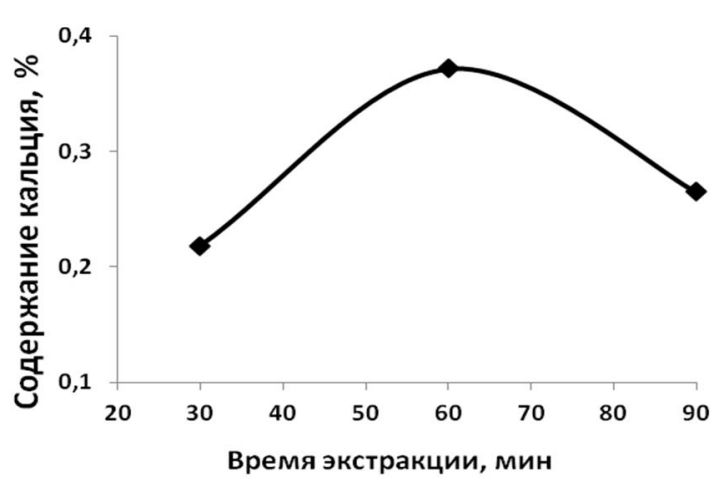

Рис. 1. Влияние времени экстракции на содержание кальция в извлечении
Таблица 2. Влияние экстрагента на извлечение кальция из плодов облепихи крушиновидной

\begin{tabular}{l|c|c}
\hline \multicolumn{1}{c|}{ Экстрагент } & $\begin{array}{c}\text { pH- } \\
\text { экстрагента }\end{array}$ & $\begin{array}{c}\text { Содержание } \\
\text { кальция, \% }\end{array}$ \\
\hline $\begin{array}{l}\text { Вода очищенная } \\
\text { Кислота } \\
\begin{array}{l}\text { хлористоводородная } \\
\text { разведеная }\end{array}\end{array}$ & $5,0-6,0$ & $0,596 \pm 0,049$ \\
\hline
\end{tabular}

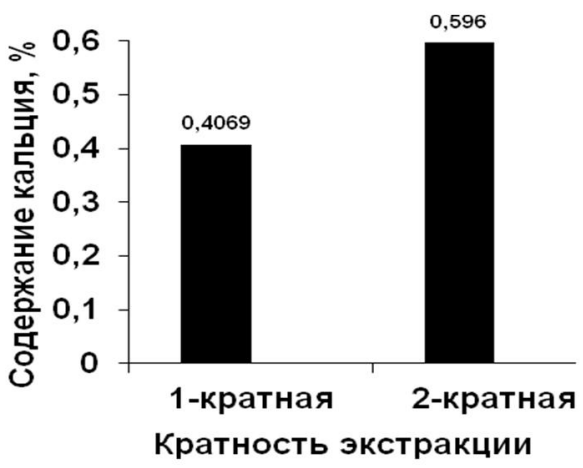

Рис. 2. Влияние кратности экстракции на извлечение кальция из плодов облепихи крушиновидной 


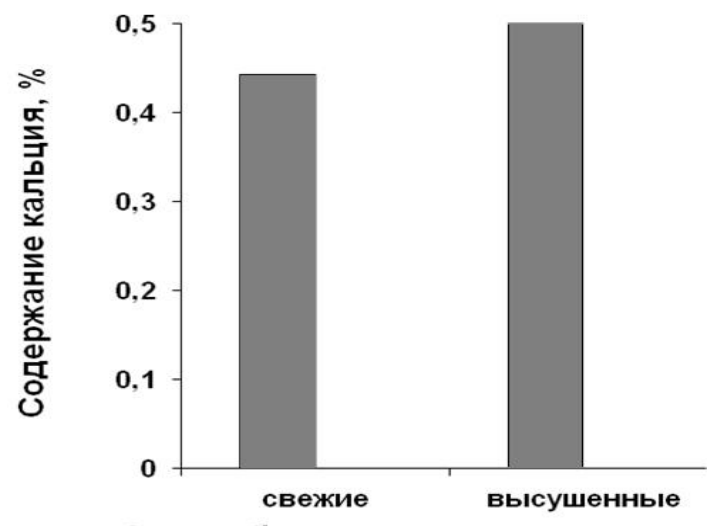

Способ консервации плодов
Рис. 3. Влияние способа консервации плодов на содержание кальция

Таблица 3. Метрологическая характеристика метода анализа $(\mathrm{P}=95 \%$; $=3)$

\begin{tabular}{c|c|c|c|c|c|c|c}
\hline $\mathrm{x}_{\mathrm{cp}}$ & $\mathrm{S}^{2}$ & $\mathrm{~S}$ & $\mathrm{Sx}_{\mathrm{cp}}$ & $\mathrm{t}(\mathrm{P}, \mathrm{t})$ & $\Delta \mathrm{x}$ & $\Delta \mathrm{x}_{\mathrm{cp}}$ & $\varepsilon_{\mathrm{cp}}, \%$ \\
\hline 1,050 & 0,00137 & 0,037 & 0,02139 & 4,30 & 0,1591 & 0,0920 & 8,76 \\
\hline
\end{tabular}

Таким образом, количество плодов облепихи, рекомендуемое для ежедневного потребления в целях восполнения суточной нормы кальция в организме человека, варьирует, согласно рекомендациям ВОЗ, от 60 до 200 г (табл. 4).

Для оценки достоверности полученные результаты были сравнены с литературными данными по определению кальция в плодах облепихи различных видов с применением как атомно-абсорбционной спектроскопии (AAC, Shimadzu, ICPQ-100), так и комплексонометрического титрования [11, 12] (табл. 5).

Таким образом, полученные экспериментальные данные сопоставимы с результатами исследований, проведенных другими авторами, как методом ААС [11], так и методом комплексонометрии [12], что свидетельствует о правомерности разработанной методики. Данные таблицы 5 демонстрируют также, что содержание кальция вариабельно в плодах облепихи даже внутри одного вида и зависит от места произрастания.

Таблица 4. Суточная норма потребления кальция (рекомендация ВО3) и плодов облепихи крушиновидной (в пересчете на абсолютно сухое сырье)

\begin{tabular}{l|c|c}
\hline \multicolumn{1}{c|}{ Рекомендация ВОЗ } & $\begin{array}{c}\text { Суточная норма } \\
\text { потребления кальция, мг }\end{array}$ & $\begin{array}{c}\text { Суточная норма потребления пло- } \\
\text { дов облепихи крушиновидной, г }\end{array}$ \\
\hline Для детей до трех лет & 600 & 60 \\
Для детей в возрасте от четырех до десяти лет & 800 & 80 \\
Для детей в возрасте от десяти до тринадцати лет & 1000 & 100 \\
Для подростков от тринадцати до шестнадцати лет & 120 & 100 \\
Для молодых людей от шестнадцати лет до двадца- & 1000 & $80-120$ \\
ти пяти лет & & $150-200$ \\
Для взрослых людей в возрасте от двадцати пяти до & $800-1200$ & $1500-2000$ \\
пятидесяти лет & & \\
Для беременных или кормящих грудью женщин & &
\end{tabular}

Таблица 5. Содержание кальция в плодах облепихи различных видов

\begin{tabular}{|c|c|c|c|}
\hline Вид облепихи & Район произрастания & Метод определения & Содержание кальция \\
\hline Облепиха среднеазиатская [11] & Провинция Ганьсу (Китай) & $\mathrm{AAC}$ & $317,44-368,44$ мг/кг \\
\hline Облепиха китайская [11] & Провинция Ганьсу (Китай) & AAC & 3119,33 мг/кг \\
\hline $\begin{array}{l}\text { Облепиха крушиновидная } \\
\text { (подвид - туркистанская) [12] }\end{array}$ & Северные районы Пакистана & Комплексонометрия & 70-125 мг/л \\
\hline $\begin{array}{l}\text { Облепиха крушиновидная (экс- } \\
\text { периментальные данные) }\end{array}$ & Россия, Воронежская область & Комплексонометрия & 1450,05 мг/кг или 30 мг/л \\
\hline
\end{tabular}

\section{Bыводы}

1. Разработана простая, доступная методика количественного определения кальция в плодах облепихи крушиновидной, которая может быть учтена при разработке современной нормативной документации. 
2. Выбраны оптимальные условия извлечения кальция из плодов облепихи крушиновидной. Лучшим экстрагентом является разведеная кислота хлористоводородная при соотношении сырья и экстрагента $1: 50$. Оптимальное время экстракции составляет 60 мин.

3. Исследовано влияние процесса высушивания на содержание кальция в исследуемом ЛРС.

4. Результаты свидетельствуют о перспективности использования плодов облепихи различных способов консервации в практической медицине в качестве не только источника жирного масла, но и ЛРС дополнительного источника кальция.

\section{Список литературы:}

1. Лекарственные растения, сырье и фитопрепараты / под ред. С.Е. Дмитрука. Томск, 2004. Ч. І. 116 с.

2. Терещук Л.В., Павлова С.С. Получение биологически ценных продуктов из плодов облепихи // Ивестия вузов. Пищевая технология. 2000. №1. С. 46-48.

3. Сорокина А.А., Скалозубова Т.А., Марахова А.И. Определение кальция и магния в листьях и настое крапивы двудомной // Фармация. 2013. №2. С. 5-8.

4. Скалозубова Т.А., Марахова А.И., Сорокина А.А. Количественное определение кальция и магния в листьях и настое крапивы двудомной // Разработка, исследование и маркетинг новой фармацевтической продукции: сб. научных трудов. Пятигорск, 2012. С. 179-180.

5. Патент 2466387 (РФ). Способ количественного определения кальция и магния в лекарственном растительном сырье / Т.А. Скалозубова, А.И. Марахова, Н.Н. Федоровский. 10.11.2012.

6. Государственная фармакопея. ХІ изд. Вып. 2. М., 1990. С. 226-377.

7. Трубачева Л.В., Лоханина С.Ю. Определение содержания ионов кальция в водах различного типа с помощью металлоиндикаторов // Химия. 2005. №8. С. 211-222.

8. Трубачева Л.В., Лоханина С.Ю. Металлохромные индикаторы при определении содержания ионов кальция в водных растворах // Химия. 2005. №8. С. 127-136.

9. ГОСТ 1219.1-74. Метод определения содержания кальция.

10. РД 34.37.305.7-97. Раздельное определение содержания кальция и магния в присутствии железа и меди комплексонометрическим методом с индикатором кислотным хромом темно-синим.

11. Cheng Tigong, Ni Ming Kang, Li Rong, Ji Fen. Исследование биохимических свойств среднеазиатской облепихи, произрастающей в провинции Ганьсу (КНР) // Химия природных соединений. 1991. №1. С. 135-137.

12. Sabir S.M., Magsood H., Hayat Imran et set. Elemental and nutritional analysis of Sea Buckthorn (Hippophae rhamnoides ssp. turkestanica) Berries of Pakistani Origin // J. Med. Food. 2005. N8(4). Pp. 518-522.

Поступило в редакичию 24 января 2014 г.

После переработки 16 апреля 2014 г. 


\section{Trineeva O.V. , Slivkin A.I. CALCIUM DEFINITION IN FRUITS OF HIPPOPHAES RHAMNOIDES L.}

Voronezh State University, Universitetskaia pl., 1, Voronezh, 394006 (Russia), e-mail: trineevaov@mail.ru

Seabuckthorn is one of the most valuable natural sources of oils rich in carotenoids, tocopherols, essential fatty acids, as well as a large group of water and zhiro $\neg$ rastvorimyh vitamins and vitamin compounds, organic acids, minerals and other substances. Minerals as a component of the metabolism of medicinal plants dopol nnyayut and enhance their therapeutic effect on or $\neg$ ganizm. Of particular interest is the macro element calcium. Currently farmatsevtiche $\neg$ sky market offers a fairly wide as $\neg$ sortiment medicines containing calcium, but, unfortunately, almost all of them have contraindications and may cause side effects serez $\neg$ nye. Therefore, the use le $\neg$ karstvennyh plants in which the macro- and micro-elements are in bioavailable form may be effective for the normalization mineral $\neg$ nogo balance. The Russian and foreign regulatory do $\neg$ kumentah medicinal

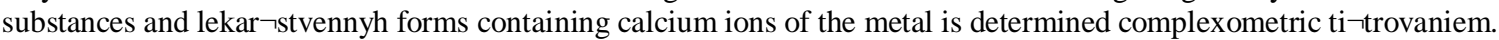

A simple, affordable method of quantitative determination of calcium in the fruit of sea buckthorn chelatometry method, which can be taken into account in the development of a modern regulatory documentation. Optimal conditions for extracting calcium from the fruit of sea buckthorn. The influence of the drying process on the calcium content in the test feedstock. Results for fresh and dried fruits were, respectively, 0.8853 and $1.0057 \%$ (based on absolutely dry raw materials) that indicate the absence of the effect of the drying process on the content of calcium in the fruit. The results suggest that the use of sea buckthorn fruit of different ways of conservation as an additional source of calcium trace element.

Keywords: calcium salts, a complexometric titration, fruits of Hippophaes rhamnoides fresh and dried up, standardization.

\section{References}

1. Lekarstvennye rasteniia, syr'e i fitopreparaty. [Medicinal plants and herbal materials]. Ed. S.E. Dmitruk. Tomsk, 2004, part I, 116 p. (in Russ.).

2. Tereshchuk L.V., Pavlova S.S. Ivestiia vuzov. Pishchevaia tekhnologiia, 2000, no. 1, pp. 46-48. (in Russ.).

3. Sorokina A.A., Skalozubova T.A., Marakhova A.I. Farmatsiia, 2013, no. 2, pp. 5-8. (in Russ.).

4. Skalozubova T.A., Marakhova A.I., Sorokina A.A. Razrabotka, issledovanie i marketing novoi farmatsevticheskoi produktsii: sb. nauchnykh trudov. [Development, research and marketing of new pharmaceutical products: collection of scientific papers]. Pyatigorsk, 2012, pp. 179-180. (in Russ.).

5. Patent 2466387 (RU). (in Russ.).

6. Gosudarstvennaia farmakopeia. [State Pharmacopoeia]. XI ed. Moscow, 1990, Issue 2. pp. 226-377. (in Russ.).

7. Trubacheva L.V., Lokhanina S.Iu. Khimiia, 2005, no. 8, pp. 211-222. (in Russ.).

8. Trubacheva L.V., Lokhanina S.Iu. Khimiia, 2005, no. 8, pp. 127-136. (in Russ.).

9. GOST 1219.1-74. Metod opredeleniia soderzhaniia kal'tsiia. [State standard 1219.1-74. Method for determination of calcium]. (in Russ.).

10. $R D$ 34.37.305.7-97. Razdel'noe opredelenie soderzhaniia kal'tsiia $i$ magniia $v$ prisutstvii zheleza $i$ medi kompleksonometricheskim metodom s indikatorom kislotnym khrom temno-sinim. [Guidance document 34.37.305.797. Separate determination of calcium and magnesium in the presence of iron and copper someone pleksonometricheskim method indicator acid chrome dark blue]. (in Russ.).

11. Cheng Tigong, Ni Ming Kang, Li Rong, Ji Fen. Khimiia prirodnykh soedinenii, 1991, no. 1, pp. 135-137. (in Russ.).

12. Sabir S.M., Magsood H., Hayat Imran et set. J. Med. Food., 2005, no. 8(4), pp. 518-522.

Received January 24, 2014

Revised April 16, 2014

\footnotetext{
* Corresponding author.
} 